\title{
GROUND STATES OF THE QUASILINEAR PROBLEMS INVOLVING THE CRITICAL SOBOLEV EXPONENT AND POTENTIALS
}

\author{
DONGSHENG KANG
}

Abstract. In this paper we study a quasilinear elliptic problem which involves the critical Sobolev exponent and multiple Hardy-type terms. By the analytic technics and variational methods, the existence and nonexistence of the ground states for the problem is established under certain assumptions.

Mathematics subject classification (2000): 35B33, 35J60, 35J65.

Keywords and phrases: quasilinear problem, ground state solution, Hardy inequality, variational method.

\section{REFERENCES}

[1] B. Abdellaoui, V. Felli, I. Peral, Existence and nonexistence for quasilinear equations involving the p-Laplacian, Boll. Unione Mat. Ital. Sez. B, 8 (2006), 445-484.

[2] B. Abdellaoui, V. Felli, I. Peral, Existence and multiplicity for perturbations of an equation involving Hardy inequality and critical Sobolev exponent in the whole $\mathbb{R}^{N}$, Adv. Differential Equations, 9 (2004), 481-508.

[3] J. Brothers, W. Ziemer, Minimal rearrangements of Sobolev functions, Acta Univ. Carolin. Math. Phys., 28 (1987), 13-24.

[4] L. Caffarelli, R. Kohn, L. Nirenberg, First order interpolation inequality with weights, Compositio Math., 53 (1984), 259-275.

[5] D. CAO, P. HAN, Solutions to critical elliptic equations with multi-singular inverse square potentials, J. Differential Equations, 224 (2006), 332-372.

[6] V. FELLI, S. TERRACINI, Elliptic equations with multi-singular inverse-square potentials and critical nonlinearity, Comm. Partial Differential Equations, 31 (2006), 469-495.

[7] V. FelLI, S. TERRACINI, Nonlinear Schrödinger equations with symmetric multi-polar potentials, Calc. Var. Partial Differential Equations, 27 (2006), 25-58.

[8] A. Ferrero, F. Gazzola, Existence of solutions for singular critical growth semilinear elliptic equations, J. Differential Equations, 177 (2001), 494-522.

[9] J. Garcia, I. Peral, Hardy inequalities and some critical elliptic and parabolic problems, J. Differential Equations, 144 (1998), 441-476.

[10] N. Ghoussoub, C. YuAn, Multiple solutions for quasilinear PDEs involving the critical Sobolev and Hardy exponents, Trans. Amer. Math. Soc., 352 (2000), 5703-5743.

[11] P. HAN, Quasilinear elliptic problems with critical exponents and Hardy terms, Nonlinear Analysis, 61 (2005), 735-758.

[12] G. Hardy, J. Littlewood, G. Polya, Inequalities, Cambridge University Press, Cambridge, UK, 1934.

[13] E. JANNELLI, The role played by space dimension in elliptic critical problems, J. Differential Equations, 156 (1999), 407-426.

[14] D. KAnG, On the quasilinear elliptic problems with critical Sobolev-Hardy exponents and Hardy terms, Nonlinear Anal., 68 (2008), 1973-1985.

[15] D. Kang, S. Peng, Positive solutions for elliptic equations with critical Hardy-Sobolev exponents, Appl. Math. Lett., 17 (2004), 411-416.

[16] P. L. Lions, The concentration compactness principle in the calculus of variations, the limit case (I), Revista Mathematica Iberoamericana, 1, 1 (1985), 145-201. 
[17] P. L. LiONS, The concentration compactness principle in the calculus of variations, the limit case (II), Revista Mathematica Iberoamericana, 1, 2 (1985), 45-121.

[18] D. SMETS, Nonlinear Schrödinger equations with Hardy potential and critical nonlinearities, Trans. Amer. Math. Soc., 357 (2005), 2909-2938.

[19] S. Terracini, On positive solutions to a class equations with a singular coefficient and critical exponent, Adv. Differential Equations, 2 (1996), 241-264.

[20] J. L. VAZQUeZ, A strong maximum principle for some quasilinear elliptic equations, Appl. Math. Optimization, 12 (1984), 191-202.

[21] M. WILLEM, Analyse fonctionnelle elementaire, Cassini Editeurs, Paris, 2003. 